\title{
The Prevalence of Smoking, Determinants and Chance of Psychological Problems among Smokers in an Urban Community Housing Project in Malaysia
}

\author{
Rusdi Abd Rashid ${ }^{1,2}$, Sharmilla Kanagasundram ${ }^{2, *}$, Mahmoud Danaee ${ }^{3}$,

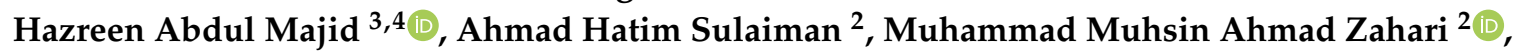 \\ Chong Guan $\mathrm{Ng}^{2} \mathbb{(}$, Benedict Francis ${ }^{2}{ }^{-}$, Wan Azlinda Irnee Wan Husin ${ }^{1}$ and Tin Tin Su ${ }^{4,5}$ \\ 1 University of Malaya Centre of Addiction Sciences (UMCAS), University of Malaya, Kuala Lumpur 50603, \\ Malaysia; rusdi@ummc.edu.my (R.A.R.); irnee84_umcas@um.edu.my (W.A.I.W.H.) \\ 2 Department of Psychological Medicine, Faculty of Medicine, University of Malaya, Kuala Lumpur 50603, \\ Malaysia; hatim@um.edu.my (A.H.S.); muhsin@ummc.edu.my (M.M.A.Z.); \\ chong_guan@um.edu.my (C.G.N.); ben.franciscan@gmail.com (B.F.) \\ 3 Department of Social and Preventive Medicine, Faculty of Medicine, University of Malaya, \\ Kuala Lumpur 50603, Malaysia; mdanaee@um.edu.my (M.D.); hazreen@ummc.edu.my (H.A.M.) \\ 4 Centre for Population Health (CePH), Department of Social and Preventive Medicine, Faculty of Medicine, \\ University of Malaya, Kuala Lumpur 50603, Malaysia; tstin@ummc.edu.my \\ 5 South East Asia Community Observatory (SEACO), Monash University Malaysia, \\ Bandar Sunway 47500, Malaysia \\ * Correspondence: sharmilla_kanagasundram@yahoo.com
}

Received: 4 April 2019; Accepted: 15 May 2019; Published: 18 May 2019

\begin{abstract}
Objective: This study was conducted to assess the prevalence, pattern of smoking and sociodemographic factors among Kerinchi residents in Kuala Lumpur, as well as to identify the association between smoking, stress, anxiety and depression. Methods: This study was carried out at four community housing projects in the Lembah Pantai area in Kuala Lumpur. Data was collected between 3 February 2012, and 29 November 2012. Data collectors made house visits and used interviewer administered questionnaires containing questions on demographic data and smoking patterns. Depression anxiety stress scale (DASS) was used to assess psychological symptoms. Alcohol smoking and substance involvement screening tool (ASSIST) scale was used to assess nicotine use. Results: Data from 1989 individuals (833 households) showed the age of respondents ranged from 18 to 89 years and the mean age was 39.12 years. There were 316 smokers indicating the prevalence of smoking was $15.85 \%$, with $35.5 \%$ among males and $1.8 \%$ among females. Further, $86.6 \%$ of smokers were Malay and $87 \%$ were Muslims. Divorce was associated with smoking. Unemployment and housewives were less associated with smoking. Depression and anxiety were significantly associated with smoking (OR = 1.347. 95\% CI: 1.042-1.741) and (OR = 1.401. 95\% CI: 1.095-1.793) respectively. Conclusion: Screening for depression and anxiety should be routinely performed in the primary care setting and in population-based health screening to intervene early in patients who smoke.
\end{abstract}

Keywords: smoking; self-medication; depressive behaviors; poor coping

\section{Introduction}

According to the literature, tobacco use started in the fifteenth century. Initially, it was used for pleasure and was even proclaimed to have medicinal uses [1]. However, it is now known that there are many hazardous compounds in cigarette smoke [2] which cause a great deal of morbidity [3]. It is of great concern that those individuals who are unable to cope with mental stress use tobacco to get 
psychological relief [4]. This is due to the fact that tobacco has been shown to have antidepressant effects [5]. However, this is a maladaptive way of coping as smoking has been shown to decrease life span [6]. Fortunately, statistics show that cigarette use in Malaysia has been decreasing over the last few years [7].

Tobacco use is one of the major preventable areas of morbidity and this lead to considerable research being undertaken to assess the prevalence of its use in Malaysia and the world [8]. A study by Hock et al. (2013) [7] showed that 46.5\% of the adult population in Malaysia aged 18 years and above smoked. Social determinants have been shown to play a large role. Smoking is not equal among the various social determinants, and is prevalent among people living in poverty [9].

Previous research has shown that nicotine has strong associations with psychiatric morbidity such as stress, anxiety and depression [10-12]. People living in poverty have less access to healthcare [13] and hence, nicotine becomes a useful way for them to self- medicate. This alarming fact brings an urgency for health care providers and researchers to find specific interventions and comprehensive health programs in order to overcome this issue. In order to overcome this extensive problem, specific knowledge such as demographic details and targeted intervention, is required to prevent or mitigate the usage of nicotine.

Research indicates that $80 \%$ of smokers come from low and middle income countries [9]. The Kerinchi community was chosen because Kerinchi is highly populated and comprises people of lower socioeconomic status compared to other areas in Kuala Lumpur. A low level of education and low income, makes one susceptible to smoking $[14,15]$. In addition to the above mentioned factors, other demographic characteristics such as age, gender, marital status, religion and size of the family are factors that may influence the use of the substance $[7,16]$. Thus, the importance of this study is to shed light on the number, characteristics and pattern of smokers among the Kerinchi community, and also assess if there is any association between smoking and stress, anxiety and depression.

\subsection{Objective}

(1) To identify the prevalence and pattern of smoking among Kerinchi residents in Kuala Lumpur.

(2) To identify the association between sociodemographic factors and smoking among Kerinchi residents in Kuala Lumpur.

(3) To identify the association between stress, anxiety and depression, and smoking among Kerinchi residents in Kuala Lumpur.

\subsection{Hypothesis}

There is an association between prevalence of smoking, socioeconomic factors, depression and anxiety among smokers residing in Kerinchi, Kuala Lumpur.

\section{Methodology}

\subsection{Setting}

This study was carried out at 4 community housing projects, that is, Projek Perumahan Rakyat (PPR) in the Lembah Pantai area in Kuala Lumpur were the population sample in this study. There were four PPR involved which were PPR Kerinchi, PPR Seri Cempaka, PPR Pantai Ria and PPR Seri Pantai. This study was funded by the Municipality in Kuala Lumpur as part of the squatter resettlement program. The requirements to obtain a housing unit in the PPR were that a family (1) must have at least 1 child, (2) should earn less that RM 2000 (RM = Ringgit Malaysia) and (3) should not own a property within $35 \mathrm{~km}$ from the capital city. All data collection procedures were approved by the Institutional Review Board at University of Malaya (IRB protocol MEC Ref number 890.161). 


\subsection{Data Collection}

The sampling method used in this study was universal sampling and therefore all participants from the households surveyed were included in this study. The time frame for data collection was 3 February 2012, to 29 November 2012. Data collectors went from house to house to collect data using interviewer administered questionnaires. The questionnaires which were in Malay and English contained questions on demographic data and smoking patterns. In addition, Depression anxiety stress scale (DASS) was used to assess psychological symptoms in the sample. Alcohol smoking and substance involvement screening tool (ASSIST) was used to assess nicotine use.

Psychological problems: Psychological problems were characterized as being stress, depression and anxiety [17].

Nicotine Abuse: Maladaptive pattern of use indicated by continued use despite knowledge of having a persistent or recurrent social, occupational, psychological or physical problem that is caused or exacerbated by the recurrent use in situations in which it is physically hazardous [18].

Poverty: People that have less information, less resource, less able to access health care, less nourished, have a higher risk of illness and disability (World Health Organization, 2013) [19].

\subsection{Scales Used}

Depression anxiety stress scales (DASS) consist of a list of 21 symptoms, each of which is to be rated on a four point scale of how much the patient had that symptom in the last week [20]. This scale is investigator administered.

Alcohol smoking and substance involvement screening tool (ASSIST) scale was used to assess nicotine abuse [21].

\subsection{Statistical Analyses}

All statistical analyses were performed using IBM SPSS Statistics for Windows, version 25.0 (IBM Corp LP, Armonk, NY, USA). Descriptive statistics, such as frequency and percentage, were applied for categorical data. Inferential statistics, including Chi square test, univariate and stepwise multivariate logistic regression, were carried out to study the relationship between variables and outcome (smoker vs non-smoker). A $p$-value of $\leq 0.05$ was considered statistically significant.

\section{Results}

\subsection{Descriptive Analyses}

3.1.1. To Identify the Prevalence and Pattern of Smoking among Kerinchi Residents in Kuala Lumpur

The data from 1989 individuals (833 households) were collected in the household survey in the PRPs. The age of respondents in this study ranged from 18 years to 89 years. The mean age of the respondents in this study was 39.12. Descriptive analysis was completed to analyze the demographic characteristic of the respondents (Table 1). Slightly more than half of the respondents in this study were female, that is, $1054(53.0 \%)$ were female and $935(47.0 \%)$ were male. In respect of ethnicity, most of the respondents were Malay, with 1608 (80.8\%) being Malay, followed by $339(17 \%)$ being Indian and $21(1.1 \%)$ being Chinese. 
Table 1. Distribution of demographic variables.

\begin{tabular}{|c|c|c|c|}
\hline Sociodemographic Characteristics & $\begin{array}{c}\text { Non-Smoker } \\
n(\%)\end{array}$ & $\begin{array}{c}\text { Smoker } \\
n(\%)\end{array}$ & $p$-Value \\
\hline \multicolumn{4}{|l|}{ Age } \\
\hline 18 to 29 & $547(84.3 \%)$ & $102(15.7 \%)$ & 0.427 \\
\hline 30 to 39 & $326(80.7 \%)$ & $78(19.3)$ & \\
\hline 40 to 49 & $349(81.2 \%)$ & $81(18.8 \%)$ & \\
\hline 50 to 59 & $254(80.9(\%)$ & $60(19.1 \%)$ & \\
\hline 60 and above & $162(84.4 \%)$ & $30(15.6 \%)$ & \\
\hline \multicolumn{4}{|l|}{ Gender } \\
\hline Male & $603(64.5 \%)$ & $332(35.5 \%)$ & $<0.001$ \\
\hline Female & $1035(98.2 \%)$ & $19(1.8 \%)$ & \\
\hline \multicolumn{4}{|l|}{ Ethnicity } \\
\hline Malay & $1304(81.1 \%)$ & $304(18.9 \%)$ & 0.037 \\
\hline Chinese & $18(85.7 \%)$ & $3(14.3 \%)$ & \\
\hline Indian & $298(87.9 \%)$ & $41(12.1 \%)$ & \\
\hline Other Bumiputra & $5(100 \%)$ & $0(\%)$ & \\
\hline Others & $13(81.3 \%)$ & $3(18.8 \%)$ & \\
\hline \multicolumn{4}{|l|}{ Religion } \\
\hline Islam & $1322(81.2 \%)$ & $307(18.8 \%)$ & 0.042 \\
\hline Christian & $19(82.6 \%)$ & $4(17.4 \%)$ & \\
\hline Buddhist & $18(85.7 \%)$ & $3(14.3 \%)$ & \\
\hline Hindu & $276(88.5 \%)$ & $36(11.5 \%)$ & \\
\hline Sikh & $3(75.0 \%)$ & $1(25.0 \%)$ & \\
\hline \multicolumn{4}{|l|}{ Education Level } \\
\hline No formal Education & $127(85.2 \%)$ & $22(14.8 \%)$ & 0.073 \\
\hline Primary School & $194(81.9 \%)$ & $43(18.1 \%)$ & \\
\hline Secondary School & $978(80.8 \%)$ & $232(19.2 \%)$ & \\
\hline Tertiary & $339(86.3 \%)$ & $54(13.7 \%)$ & \\
\hline \multicolumn{4}{|l|}{ Marital Status } \\
\hline Married & $966(79.2 \%)$ & $254(20.8 \%)$ & $<0.001$ \\
\hline Divorced & $92(94.8 \%)$ & $5(5.2 \%)$ & \\
\hline Widow & $74(96.1 \%)$ & $3(3.9 \%)$ & \\
\hline Single & $506(85.0 \%)$ & $89(15 \%)$ & \\
\hline \multicolumn{4}{|l|}{ Status Occupation } \\
\hline Civil Servant & $105(76.6 \%)$ & $32(23.4 \%)$ & $<0.001$ \\
\hline Private Sector & $700(79.0 \%)$ & $186(21.0 \%)$ & \\
\hline Self-employed & $135(69.2 \%)$ & $60(30.8 \%)$ & \\
\hline Student & $134(94.4 \%)$ & $8(5.6 \%)$ & \\
\hline Housewife & $158(77.1 \%)$ & $47(22.9 \%)$ & \\
\hline Unemployed & $360(98.9 \%)$ & $4(1.1 \%)$ & \\
\hline Retiree & $46(76.7 \%)$ & $14(23.3 \%)$ & \\
\hline
\end{tabular}

A total of 351 respondents were tobacco product users and 316 were smokers which indicated that the prevalence of smoking among Kerinchi residents in Kuala Lumpur was 15.85\%, and tobacco product use was at $17.64 \%$. Prevalence of smoking among males was $35.5 \%$ and only $1.8 \%$ of females smoked. Among smokers, $86.6 \%$ were Malay, $87 \%$ were Muslims, $84 \%$ were male and $29 \%$ were in the 18 to 29 age group. Regarding the other Bumiputra, 2 were from Sabah and 3 from Sarawak.

Several characteristics related to smoking behaviors were studied (Table 2) and results showed that the majority of respondents were introduced initially through friends (75.8\%). Regarding the frequency of usage, $82.3 \%$ smoked daily. 
Table 2. Patterns of smoking among respondents.

\begin{tabular}{|c|c|c|c|}
\hline Variable & Level & Frequency & Percent \\
\hline \multirow{3}{*}{ Route of administration } & Oral & 18 & 5.1 \\
\hline & Smoking & 316 & 90 \\
\hline & N/A & 17 & 4.8 \\
\hline \multirow{4}{*}{ Who introduced you to smoking? } & Friends & 266 & 75.8 \\
\hline & Other family member & 3 & 0.9 \\
\hline & Acquaintance & 19 & 5.4 \\
\hline & NA & 63 & 17.7 \\
\hline \multirow{5}{*}{ How frequent is the usage } & Once or twice ever & 27 & 7.7 \\
\hline & Once a month & 4 & 1.1 \\
\hline & Once a week & 6 & 1.7 \\
\hline & Everyday or almost every day & 289 & 82.3 \\
\hline & $\mathrm{N} / \mathrm{A}$ & 25 & 7.2 \\
\hline \multirow{5}{*}{$\begin{array}{l}\text { How frequently the usage brought } \\
\text { problems }\end{array}$} & Never & 232 & 66.1 \\
\hline & Once or twice & 47 & 13.2 \\
\hline & A month & 11 & 3.1 \\
\hline & A week & 15 & 4.3 \\
\hline & Everyday or almost every day & 46 & 13.1 \\
\hline \multirow{5}{*}{$\begin{array}{l}\text { How frequently the smoking makes you } \\
\text { fail performing daily routine }\end{array}$} & Never & 303 & 86.3 \\
\hline & Once or twice & 27 & 7.7 \\
\hline & A month & 4 & 1.1 \\
\hline & A week & 2 & 0.6 \\
\hline & Everyday or almost every day & 15 & 3.7 \\
\hline \multirow{3}{*}{ Anybody concerned about this usage? } & Never & 73 & 20.8 \\
\hline & Yes, but not in the past 3 months & 88 & 25.1 \\
\hline & Yes, in the past 3 months & 190 & 54.1 \\
\hline \multirow{3}{*}{ Tried to quit but couldn't control } & Never & 106 & 30.2 \\
\hline & Yes, but not in the past 3 months & 77 & 21.9 \\
\hline & Yes, in the past 3 months & 168 & 47.9 \\
\hline
\end{tabular}

3.1.2. To Identify the Association between Sociodemographic Factors and Smoking among Kerinchi Residents in Kuala Lumpur

To evaluate the relationship between sociodemographic variables and smoking status (Table 3), Chi square test was used. The results indicated that, except for age $\left(\chi^{2}=3.851, p=0.427\right)$ and educational level $\left(\chi^{2}=6.959, p=0.037\right)$ which were not significantly correlated with smoking status, all other variables were significantly associated with smoking status. Regarding gender, the majority of smokers were male (94.6\%) and results indicated that there is a significant association between gender and smoking $\left(\chi^{2}=387.315, p<0.001\right)$. According to these results, it was found that smoking status was significantly correlated with ethnicity $\left(\chi^{2}=10.192, p=0.037\right)$, religion $\left(\chi^{2}=9.935, p=0.042\right)$, marital status $\left(\chi^{2}=31.845, p<0.001\right)$ and occupational status $\left(\chi^{2}=120.961, p<0.001\right)$.

Based on the results of univariate analysis, significantly associated factors were applied in a stepwise multivariate logistic regression and the results showed that four factors significantly predicted smoking among respondents. According to these results, females had a significantly less chance of being a smoker compared to a male respondent ( $\mathrm{OR}=0.39 .95 \% \mathrm{CI}: 0.023-0.066)$. Ethnic groups were not significantly affected by smoking. The chance of smoking among divorced respondents was significantly higher than married respondents $(\mathrm{OR}=1.999 .95 \% \mathrm{CI}: 1.310-3.050)$. The last significant factor was occupation in which only two groups, housewives (OR $=0.242 .95 \%$ CI: $0.097-0.606)$ and those unemployed (OR $=0.228 .95 \% \mathrm{CI}$ : $0.072-0.723$ ) had a lower chance of smoking compared to a civil servant as a reference group. 
Table 3. Results of stepwise multivariate logistic regression between sociodemographic characteristics and smoking.

\begin{tabular}{|c|c|c|c|c|}
\hline \multirow{2}{*}{ Sociodemographic Characteristics } & \multirow{2}{*}{$p$-Value } & \multirow{2}{*}{ OR } & \multicolumn{2}{|c|}{$95 \%(C I)$} \\
\hline & & & Lower & Upper \\
\hline \multicolumn{5}{|l|}{ Gender } \\
\hline Male & \multicolumn{4}{|c|}{ Reference } \\
\hline Female & 0.0001 & 0.039 & 0.023 & 0.066 \\
\hline \multicolumn{5}{|l|}{ Ethnicity } \\
\hline Malay & \multicolumn{4}{|c|}{ Reference } \\
\hline Chinese & 0.804 & 1.302 & 0.162 & 10.490 \\
\hline India & 0.751 & 0.727 & 0.101 & 5.215 \\
\hline Other Bumiputra & 0.999 & 0.000 & 0.000 & \\
\hline Others & 0.696 & 1.396 & 0.261 & 7.451 \\
\hline Education level & & & & \\
\hline No formal Education & \multicolumn{4}{|c|}{ Reference } \\
\hline Primary School & 0.374 & 0.733 & 0.370 & 1.454 \\
\hline Secondary School & 0.159 & 0.636 & 0.339 & 1.194 \\
\hline Tertiary & 0.080 & 0.530 & 0.260 & 1.079 \\
\hline \multicolumn{5}{|l|}{ Marital Status } \\
\hline Married & \multicolumn{4}{|c|}{ Reference } \\
\hline Divorced & 0.001 & 1.999 & 1.310 & 3.050 \\
\hline Widow & 0.635 & 1.317 & 0.423 & 4.098 \\
\hline Single & 0.374 & 1.926 & 0.454 & 8.164 \\
\hline \multicolumn{5}{|l|}{ Occupational status } \\
\hline Civil Servant & \multicolumn{4}{|c|}{ Reference } \\
\hline Private Sector & 0.293 & 0.766 & 0.466 & 1.259 \\
\hline Self-employed & 0.559 & 1.190 & 0.664 & 2.132 \\
\hline Student & 0.338 & 0.666 & 0.290 & 1.529 \\
\hline Housewife & 0.002 & 0.242 & 0.097 & 0.606 \\
\hline Unemployed & 0.012 & 0.228 & 0.072 & 0.723 \\
\hline Retire & 0.270 & 1.428 & 0.758 & 2.689 \\
\hline
\end{tabular}

3.1.3. To Identify the Association between Depression Anxiety and Stress Scales and Smoking among Kerinchi Residents in Kuala Lumpur

The last research objective for the current study was related to investigating the relationship between depression, anxiety and stress with smoking. Results of the multivariate logistic regression (Table 4) showed that respondents with depression had a significantly higher chance of being smokers compared to respondents without depression (OR $=1.347 .95 \% \mathrm{CI}$ : 1.042-1.741). Further, respondents with anxiety had a significantly higher chance of being smokers compared to respondents without anxiety (OR $=1.401 .95 \% \mathrm{CI}$ : 1.095-1.793). This finding showed that respondents with stress had a higher chance of being smokers compared to respondents without stress (OR $=1.211$. 95\% CI: 0.939-1.560), but it was not statistically significant at a 0.05 level.

Table 4. Relationship between Depression Anxiety Stress Scale and smoking.

\begin{tabular}{ccccccc}
\hline $\begin{array}{c}\text { Psychological } \\
\text { Problems }\end{array}$ & Smoker (\%) & $\begin{array}{c}\text { Non-Smoker } \\
\mathbf{( \% )}\end{array}$ & $p$-Value & $\begin{array}{c}\text { Crude OR } \\
\mathbf{( 9 5 \% ~ C I )}\end{array}$ & $p$-Value & $\begin{array}{c}\text { Adjusted OR } \\
\mathbf{( 9 5 \%} \text { CI) }\end{array}$ \\
\hline No Depression & $1252(83.5 \%)$ & $248(16.5 \%)$ & reference & & & \\
Depression & $386(78.9 \%)$ & $103(21.1 \%)$ & 0.123 & $1.308(0.944-1.622)$ & 0.014 & $1.347(1.042-1.741)$ \\
\hline No Anxiety & $1199(83.8 \%)$ & $232(16.2 \%)$ & reference & & & \\
Anxiety & $439(78.7 \%)$ & $119(21.3 \%)$ & 0.047 & $1.308(1.003-1.705)$ & 0.005 & $1.401(1.095-1.793)$ \\
\hline No Stress & $1211(83.1 \%)$ & $246(16.9 \%)$ & reference & & & \\
Stress & $427(80.3 \%)$ & $105(19.7 \%)$ & 0.699 & $1.055(0.804-1.385)$ & 0.080 & $1.211(0.939-1.56)$ \\
\hline
\end{tabular}




\section{Discussion}

\subsection{Prevalence of Smoking among Adult Men and Women}

In Malaysia, only a few studies have examined the prevalence of smoking in the general population, with most studies focusing on adolescents. Among those studies is the study published in 2014 by Al-Naggar et al. [22] assessing prevalence of smoking in Malaysia among the general public with data collection completed between June 2012 to September 2012. Both the Al-Naggar et al. (2014) study and this study have a few similarities, namely that data collection was by face to face interview and the time period was in 2012. Both Shah Alam and Kerinchi have predominantly Malay inhabitants, and both locations are urban areas, with Kerinchi being of low socioeconomic status, while some areas of Shah Alam are affluent. The difference between these two studies was the location of the collection of data. The Al-Naggar et al. (2014) [22] study collected data at a restaurant while our study collected data at home. The prevalence of tobacco use in our study was only $17.64 \%$, and this is much lower than the study by Al-Naggar et al. (2014) [22] where the prevalence of smoking was 57\%. This higher value may be due to the respondents being at a restaurant, and may not have the chance to conceal that they are smokers when approached by the interviewers. In addition, if respondents are sitting with their friends who are also smokers, they may be more likely to be open compared to our study where the respondents were approached at home and may have to conceal smoking from their families. Hence, it is proposed that location of the assessment may be important. In 2011, the Global Adult Tobacco Survey (GATS) [23] estimated that approximately 23\% of Malaysia's population smoked (approximately 4,844,800 persons). However, this value is closer to our result of $17.64 \%$ and is in line with the apparent decreasing use of tobacco.

In our study, $35.5 \%$ of males and $1.83 \%$ of females are smokers. In a study by Lim et al. (2013), 15,639 participants elicited a smoking prevalence of $46.5 \%$ among males, which is much higher than our study [7]. This is comparable to the study by Rampal et al. (2006) [24] and the Malaysian Non Communicable Disease Surveillance-1 in 2011 [25] which found smoking rates among males in Malaysia to be $47.2 \%$ and $40.9 \%$ respectively. These values are similar to the rates from the Global Adult Tobacco Survey (GATS) in 2011 which reported that 43.6\% of Malaysian males aged 15 years and above were current smokers [23]. The face to face interview of our study may have contributed to under reporting. In addition, there may be an increased awareness by people of the ill effects of nicotine and the carcinogenic nature of cigarettes due to social media leading to decreased use. Males were more likely to use cigarettes compared to females. This has been a consistent finding. In our study, age and level of education were not significantly correlated with smoking. Additionally, housewives and unemployed persons were less likely to smoke compared to civil servants. In a previous study conducted on 112 people working at two municipalities in Malaysia, 37.56\% of civil servants were found to have nicotine dependence [26].

\subsection{Sociodemographic Factors and Patterns of Use}

Generally, it was a Malay male in the age group of 18 to 29 who was a smoker, despite age not being statistically significant. This finding has been replicated in other studies [7]. In our study, $75.8 \%$ of smokers were introduced to the first cigarette through friends. The age of initiation into smoking in Malaysia was 18.3 years [7], with $82.3 \%$ of the respondents smoking daily and $47.9 \%$ trying to quit in the last 3 months. According to GATS (2011) [23], 48.6\% of smokers made attempts to quit in the preceding 12 months. Better interventions need to be put in place to assist quitting [7].

\subsection{Associations between Stress, Anxiety and Depression in Smoking}

An association between smoking, and depression and anxiety was found. Another study reported that feelings of sadness and loneliness were cues to smoke [26]. Major depression has been associated in the past with increased rates of daily smoking and elevated rates of nicotine dependence [27]. Anxiety has also shown to be statistically higher in smokers than non-smokers [28]. Conversely, 
cigarette smoking and nicotine dependence appeared to be risk factors for the development of some anxiety disorders, such as panic disorder or generalized anxiety disorder. This was also true for major depression [29]. Being depressed also increased the risk of the smoker to use cigarettes daily [29].

\subsection{Limitations}

Location of the assessment was at home and respondents may conceal smoking. Using face to face interviews may yield lower smoking prevalence.

\subsection{Conclusion}

The location of the assessment and not using face to face interviews may be an important factor in determining smoking prevalence. Most Malaysian smokers tend to be either young Malay males or civil servants, especially those who are divorced. More comprehensive anti-smoking policy measures are needed in order to assist those intending to quit. Depression and anxiety, but not stress, were significantly associated with smokers.

\section{Conclusions}

This study demonstrates that the chance of depression and anxiety is prevalent, especially amongst Malay men who smoke and who are also from a low socioeconomic class. Therefore, it is recommended that screening for depression and anxiety should be routinely performed in the primary care setting and in the population based health screening to intervene early in patients who smoke.

Author Contributions: R.A.R. and T.T.S. conceived and designed the study. W.A.I.W.H., H.A.M. and T.T.S. were involved in data collection; M.D. conducted statistical analysis. All authors were responsible for drafting this paper and approving the final paper.

Funding: Participatory Action Research through Negotiation and Empowerment of the Residents (PARTNER) team and this research was supported by University of Malaya, Flagship project FL009-2011 and MRUN-2019-001/2.

Acknowledgments: This research was supported by University of Malaya Flagship project FL009-2011 and MRUN-2019-001/2. The authors thank the authorities from the City Hall Kuala Lumpur, Community Housing Management Committee, the participants of the study and the PARTNER research team.

Conflicts of Interest: The authors declare no conflicts of interest.

\section{References}

1. Gately, I. Tobacco: A Cultural History of How an Exotic Plant Seduced Civilization, 1st ed.; Grove Press: New York, NY, USA, 2002.

2. Talhout, R.; Schulz, T.; Florek, E.; Van Benthem, J.; Wester, P.; Opperhuizen, A. Hazardous compounds in tobacco smoke. Int. J. Environ. Res. Public Health 2011, 8, 613-628. [CrossRef]

3. Beaglehole, R.; Bonita, R.; Horton, R.; Adams, C.; Alleyne, G.; Asaria, P.; Baugh, V.; Bekedam, H.; Billo, N.; Casswell, S.; et al. Priority actions for the non-communicable disease crisis. Lancet 2011, 377, 1438-1447. [CrossRef]

4. Parrott, A.C. Does cigarette smoking cause stress? Am. Psychol. 1999, 54, 817. [CrossRef] [PubMed]

5. Vázquez-Palacios, G.; Bonilla-Jaime, H.; Velázquez-Moctezuma, J. Antidepressant effects of nicotine and fluoxetine in an animal model of depression induced by neonatal treatment with clomipramine. Neuro-Psychopharmacol. Biol. Psychiatry 2005, 29, 39-46. [CrossRef]

6. Doll, R.; Peto, R.; Boreham, J.; Sutherland, I. Mortality in relation to smoking: 50 years' observations on male British doctors. BMJ 2004, 328, 1519. [CrossRef]

7. Lim, H.K.; Ghazali, S.M.; Kee, C.C.; Lim, K.K.; Chan, Y.Y.; Teh, H.C.; Yusoof, A.F.M.; Kaur, G.; Zain, Z.M.; Mohamad, M.H.N.; et al. Epidemiology of smoking among Malaysian adult males: Prevalence and associated factors. BMC Public Health 2013, 13, 8. [CrossRef]

8. Jamal, A.; Agaku, I.T.; O'Connor, E.; King, B.A.; Kenemer, J.B.; Neff, L. Current cigarette smoking among adults-United States, 2005-2013. MMWR. Morb. Mortal. Wkly. Rep. 2014, 63, 1108-1112. [PubMed] 
9. Hosseinpoor, A.R.; Parker, L.A.; Tursan; d'Espaignet, E.; Chatterji, S. Social Determinants of Smoking in Lowand Middle-Income Countries: Results from the World Health Survey. PLoS ONE 2011, 6, e20331. [CrossRef]

10. Parrott, A.C. Smoking cessation leads to reduced stress, but why? Int. J. Addict. 2005, 30, 1509-1516. [CrossRef]

11. Patton, G.C.; Carlin, J.B.; Coffey, C.; Wolfe, R.; Hibbert, M.; Bowes, G. Depression, anxiety, and smoking initiation: A prospective study over 3 years. Am. J. Public Health 1998, 88, 1518-1522. [CrossRef]

12. Clancy, N.; Zwar, N.; Richmond, R. Depression, smoking and smoking cessation: A qualitative study. Fam. Pract. 2013, 30, 587-592. [CrossRef] [PubMed]

13. Peters, D.H.; Garg, A.; Bloom, G.; Walker, D.G.; Brieger, W.R.; Rahman, M.H. Poverty and access to health care in developing countries. Annal. N. Y. Acad. Sci. 2008, 1136, 161-171. [CrossRef] [PubMed]

14. Escobedo, L.G.; Peddicord, J.P. Smoking prevalence in US birth cohorts: The influence of gender and education. Am. J. Public Health 1996, 86, 231-236. [CrossRef]

15. Widome, R.; Joseph, A.M.; Hammett, P.; Van Ryn, M.; Nelson, D.B.; Nyman, J.A.; Fu, S.S. Associations between smoking behaviors and financial stress among low-income smokers. Prev. Med. Rep. 2015, 2, 911-915. [CrossRef] [PubMed]

16. Harrell, J.S.; Bangdiwala, S.I.; Deng, S.; Webb, J.P.; Bradley, C. Smoking initiation in youth: The roles of gender, race, socioeconomics, and developmental status. J. Adolesc. Health 1998, 23, 271-279. [CrossRef]

17. Kalman, D.; Morissette, S.B.; George, T.P. Co-morbidity of smoking in patients with psychiatric and substance use disorders. Am. J. Addict. 2005, 14, 106-123. [CrossRef] [PubMed]

18. American Psychiatric Association. Diagnostic and Statistical Manual of Mental Disorders (DSM-5 $\left.{ }^{\circledR}\right)$; American Psychiatric Association Publishing: Washington, DC, USA, 2013.

19. Measuring Core Health Indicators in the South East Asia Region. World Health Organization Regional Office for South East Asia, 2014.

20. Brown, T.A.; Chorpita, B.F.; Korotitsch, W.; Barlow, D.H. Psychometric properties of the Depression Anxiety Stress Scales (DASS) in clinical samples. Behav. Res. Ther. 1997, 3, 79-89. [CrossRef]

21. Humeniuk, R.E.; Ali, R.A.; Babor, T.F.; Farrell, M.; Formigoni, M.L.; Jittiwutikarn, J.; Boerngen de Larcerda, R.; Ling, W.; Marsden, J.; Monteiro, M.; et al. Validation of the Alcohol Smoking and Substance Involvement Screening Test (ASSIST). Addiction 2008, 103, 1039-1047. [CrossRef]

22. Al-Naggar, R.A.; Bobryshev, Y.V.; Anil, S. Pattern of shisha and cigarette smoking in the general population in Malaysia. Asian Pac. J. Cancer Prev. 2014, 15, 10841-10846. [CrossRef] [PubMed]

23. Institute for Public Health (IPH). Report of the Global Adult Tobacco Survey (GATS) Malaysia; Ministry of Health Malaysia: Putrajaya, Malaysia, 2012.

24. Rampal, L.; Sanjay, R.; Azhar, M.D.Z. A National study on the prevalence and factors associated with smoking among 17,246 Malaysians aged 18 years and above. In Proceedings of the 13th World Conference on Tobacco and Health, Washington, DC, USA, July 2006.

25. WHO. NCD Surveillance in ASEAN Countries 2011; WHO: Geneva, Switzerland, 2011.

26. Suriani, A.F.; Hejar, I.; Abidin, A.R.; Saliluddin, S.M. The association between nicotine dependence and smoking practices among Malay male smokers working in Selangor municipalities. Int. J. Public Health Clin. Sci. 2015, 2, 17-28.

27. Fergusson, D.; Goodwin, R.; Horwood, L. Major depression and cigarette smoking: Results of a 21-year longitudinal study. Psychol. Med. 2003, 33, 1357-1367. [CrossRef] [PubMed]

28. McCabe, R.E.; Chudzik, S.M.; Antony, M.M.; Young, L.; Swinson, R.P.; Zolvensky, M.J. Smoking behaviors across anxiety disorders. J. Anxiety Dis. 2004, 18,7-18. [CrossRef]

29. Breslau, N.; Peterson, E.L.; Schultz, L.R.; Chilcoat, H.D.; Andreski, P. Major depression and stages of smoking: A longitudinal investigation. Arch. Gen. Psychiatry 1998, 55, 161-166. [CrossRef]

(C) 2019 by the authors. Licensee MDPI, Basel, Switzerland. This article is an open access article distributed under the terms and conditions of the Creative Commons Attribution (CC BY) license (http://creativecommons.org/licenses/by/4.0/). 